\title{
Niche evolution of the Neotropical tree genus Otoba in the context of global biogeography of the nutmeg family, Myristicaceae
}

Running title: Biogeography of Otoba and Myristicaceae

Laura Frost, Daniel A. Santamaría-Aguilar, Daisy Singletary, \& Laura P. Lagomarsino

Shirley C. Tucker Herbarium, Department of Biological Sciences, Louisiana State University, Baton Rouge, LA 70808, USA

1author for communication: llagomarsino1@lsu.edu

\section{Acknowledgements}

This research was funded by a Louisiana Board of Regents Research Competitiveness Subprogram grant and by the LSU Department of Biological Sciences. We would like to thank the Missouri Botanical Garden (MO) for their access to their important collections, and Reinaldo Aguilar, Rudy Gelis, Timothy Paine, and John Janovec for permission to use their photographs. We thank Brant Faircloth, Matthew Johnson, Carl Oliveros, and Jessie Salter for their guidance in library preparation and Brant Faircloth for access to laboratory equipment, and LSU HPC for computational resources. This manuscript benefited from feedback from Laymon Ball, Janet Mansaray, and Diego Paredes-Burneo. 


\begin{abstract}
Aim Plant distributions are influenced by the ability to colonize new areas via long-distance dispersal or adapt to new environments via niche evolution. We use Otoba (Myristicaceae), a tree genus that is ecologically dominant in low-to-mid elevation wet forests, as a system to understand these processes within the Neotropics, a region characterized by high species richness and a diversity of biomes.
\end{abstract}

Location Neotropics and global

Taxon Otoba and broader Myristicaceae

Methods We use a universal sequence capture probset to infer the first phylogeny of Otoba from herbarium specimens. We further place Otoba within the context of Myristicaceae by inferring the most densely sampled phylogeny of the family to date using publicly available sequence data. We subsequently use both phylogenies to infer biogeography of Myristicaceae and Otoba, and examine patterns of niche evolution within Otoba, using phylogenetic comparative methods.

Results Myristicaceae has an Old World origin, with a single dispersal event to the Neotropics that resulted in a strongly supported Neotropical clade with Otoba sister to the remaining genera. Divergence dates, fossil evidence, and a notable lack of long-distance dispersal events are consistent with a Boreotropical origin of Neotropical Myristicaceae. Mirroring the rarity of dispersal at the family level, Otoba's biogeography is marked by relatively few dispersal events, but rapid niche evolution within wet tropical biomes.

Main conclusions Contrasting with previous studies, long-distance dispersal does not need to be invoked to explain the pantropical distribution of Myristicaceae. Mirroring limited dispersal within the family, Otoba is a recent, rapid radiation that only traversed the Andes a single time, likely a product of its relatively large seeds that rely on large-bodied vertebrates for dispersal. Otoba's biogeographic history suggests that key aspects of the Neotropical landscape - namely the uplift of the Andean mountains and the formation of the Isthmus of Panama- structured relationships. These results have implications for assembly of the flora of the Neotropics more broadly, and highlight the role of niche evolution in wet tropical biomes.

\title{
Keywords
}

Boreotropics; herbariomics; Magnoliales; museum-based research; natural history collections; Neotropics; phylogenomics; phylogenetic comparative methods 


\section{Significance statement}

The Neotropics house more plant species than any other region. Here, we document labile niche evolution in the ecologically important Neotropical genus Otoba, which includes species that are both hyperdominant in the Amazon and narrowly Andean endemics. The few biogeographic movements we infer in Otoba are tied to major geological events. This mirrors global biogeography of Myristicaceae in which long-distance dispersal is rare, and includes a single expansion into the Americas via a Boreotropical ancestor. This suggests a more important role of adaptation to new habitats in geographic proximity than dispersal to preadapted regions in this iconic Neotropical tree genus. 
The distribution of plant clades is controlled by a combination of biogeographic movement, the pace of environmental adaptation, and macroevolutionary dynamics (Donoghue, 2008). Movement into new regions is determined by geographic proximity and intrinsic traits that govern dispersal ability (e.g., propagule type), while adaptation to a new habitat is a product of the degree of phylogenetic niche conservatism within the lineage (Edwards \& Donoghue, 2013). Mounting evidence suggests that the degree to which plant groups disperse to new locations to which they are pre-adapted versus shift ecological tolerances to habitats in close geographic proximity is both clade and environment dependent. In some groups, like high Andean plant radiations derived from North American temperate clades (Hughes \& Eastwood, 2006; Madriñán et al., 2013; Pouchon et al., 2018) and mangroves (Woodroffe \& Grindrod, 1991), it is (to borrow a phrase from Donoghue 2008) "easier to move than evolve". In other clades, including Mimosa and other legumes in the Brazilian cerrado (Simon et al., 2009) and Montiaceae in temperate latitudes (Ogburn \& Edwards, 2015), major transitions in environmental tolerance are very common. In fact, a potentially large proportion of Amazonian biota have roots in distinct biomes (Antonelli et al., 2018). In the not distant past, both long-distance dispersal and niche evolution were thought to be rare in macroevolution (cite), empirical studies demonstrate an increasingly important role for these processes across many clade-focused studies (Donoghue \& Edwards, 2014; Nathan, 2006).

The Neotropics has been an important region for understanding the joint roles of dispersal and niche evolution in plant biogeography due to its high species richness, extreme habitat heterogeneity, and complex geologic history. In particular, the Northern Neotropics has a dramatic recent geological history, punctuated by periods of rapid mountain uplift in the Andes (Hoorn et al., 2010) and the gradual closing of the Isthmus of Panama (Bacon et al., 2015; O'Dea et al., 2016). These play complementary roles in Neotropical plant biogeography (Antonelli et al., 2009; Gentry, 1982). The formation of the Isthmus of Panama represented a continually diminishing barrier to dispersal. Before its emergence, the marine region between Central and South America was difficult for dispersal-limited species, while its completion facilitated the Great American Biotic Interchange, a period marked by high rates of dispersal between continents across a large swathe of tropical rainforest (Bacon et al., 2015). Contrastingly, the uplift of the Andes represented an increasingly steep barrier to dispersal throughout their uplift history, with greater and greater elevation separating suitable habitats on either side of a given cordillera, further exaggerated by extreme habitat heterogeneity. These mountains began their rise in the Paleocene, but major bursts of mountain building occurred more recently, 4 to 12 My ago (Garzione et al., 2008). This uplift changed local topography, continental-scale climate patterns, and landscape configuration, paving the way for dispersal corridors connecting different regions of the Neotropics, which shifted through time (Hoorn et al., 2010). This influenced diversification and biogeography in Neotropical plants, whether in montane Andean habitats (Hoorn et al., 2019; Lagomarsino et al., 2016; Pennington et al., 
2010; Särkinen, Pennington, et al., 2012) or in extra-Andean habitats, including Amazon basin (Antonelli et al., 2009; Dick et al., 2012).

We aim to study the impact of Neotropical landscape change on lineage evolution in a nutmeg relative, Otoba (Myristicaceae). Its 10 species are distributed from Nicaragua to Brazil, with the highest species richness in low Andean montane forests and lowland rainforests, especially of the Chocó region and western Amazonia (Santamaría-Aguilar et al., 2019). Otoba occurs in many different habitat types in the northern Neotropics, and spans a broad elevational range that includes the highest elevation occurrence in Myristicaceae (Jaramillo-Vivanco \& Balslev, 2020). Species can also be found in lowland rainforests, and Otoba is one of the ten most abundant genera in western Amazonia (Guevara Andino et al., 2017; ter Steege et al., 2006). Individual species can be some of the most common in many forests, including $O$. parvifolia in Madre de Díos, Peru (Pitman et al., 2017; Swamy, 2017) and Madidí, Bolivia (Macía, 2008), O. glycycarpa in Yasuní, Ecuador (Guevara Andino et al., 2017), and high várzea forest of the Amazonian floodplain in Brazil and Bolivia (Wittmann et al., 2006). This broad ecological tolerance and presence across both notable Neotropical geographic features makes Otoba a great system to understand the roles of dispersal and niche evolution in the establishment of a widespread, ecologically important group.

Otoba is distinct among Myristicaceae in many regards. Like other members of the nutmeg family, Otoba is characterized by a strong aromatic scent from essential oils, a pagodalike growth form (i.e., "Myristicaceous growth", or Massart's model (Hallé et al., 1978)), dioeciousness with small, trimerous flowers (Armstrong \& Tucker, 1986) (Fig. 1A-C), red, dilute latex $($ Fig. $1 \mathrm{H})$, and a characteristic valvate capsule that opens to reveal a large, arillate seed (Fig. 1D-E). However, within Neotropical Myristicaceae, Otoba is notable for its low-montane distribution, conduplicate vernation (Fig. 1I), and seeds that most commonly have white arils, not the more typical bright red (e.g., mace). Its pollen has a unique set of characters that are more similar to African members of the family than other Neotropical genera (Sauquet \& Le Thomas, 2003). 
bioRxiv preprint doi: https://doi.org/10.1101/2020.10.02.324368; this version posted February 26, 2021. The copyright holder for this preprint (which was not certified by peer review) is the author/funder, who has granted bioRxiv a license to display the preprint in perpetuity. It is made available under aCC-BY-NC 4.0 International license.
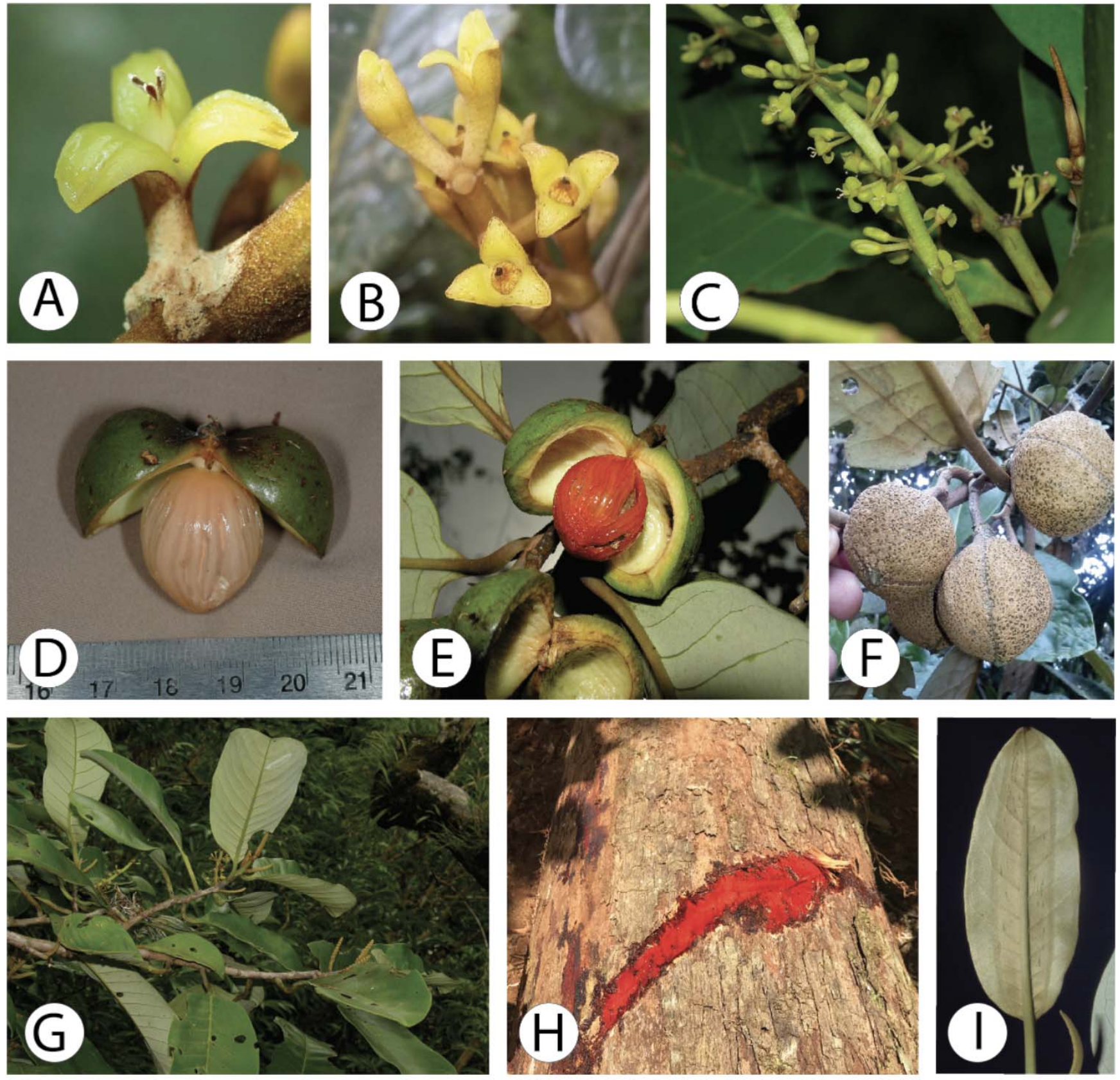

Figure 1. Morphological diversity of Otoba. A-C) Floral diversity. A) Staminate and B) pistillate flowers of O. gordoniifolia; C) Infloresence of Central American O. novogranatensis. D-F) Fruit diversity. D) Fruit from South American O. novogranatensis showing whitish aril and E) from Central American O. novogranatensis showing red aril. F) Unopened capsules of $O$. gordoniifolia. G-I) Vegetative diversity. G) Branch and $\mathrm{H}$ ) stem cut of Central American $\mathrm{O}$. novogranatensis, the latter showing characteristic red exudate. I) Leaf of $O$. parvifolia, showing vernation lines. (Photo credits: $A, B$, and $F$ by Rudy Gelis, downloaded from iNaturalist with permission; C, E, G, and H by Reinaldo Aguilar; D by Timothy Paine; and I by John Janovec.) 
Across their full diversity (comprising 21 genera and ca. 500 species), Myristicaceae are notable for their importance in ethnobotany, including as food plants (e.g., nutmeg and mace, Myristica fragrans), timber species (e.g., Virola surinamensis), and hallucinogens (e.g., epená, Virola sp. (Alrashedy \& Molina, 2016)). The large, arillate seeds are important food sources for large-bodied birds, primates, and bats, which, in turn, act as seed dispersers (Forget et al., 2000; Giraldo et al., 2007; Melo et al., 2009; Moreira et al., 2017; Russo, 2003). Though pollination is less studied, the small, usually imperfect flowers are visited by various small insects including beetles, flies, and thrips in Myristica (Armstrong \& Irvine, 1989; Sharma \& Armstrong, 2013) and Virola (Jardim \& Mota, 2007), and generalist pollinators are likely common throughout the family. Further, their abundance in lowland forests (ter Steege et al., 2006) makes Neotropical Myristicaceae an important system for understanding ecological processes that allow species coexistence in hyperdiverse communities in the western Amazon (Queenborough et al., 2007a, 2007b)). While many studies support their sister relationship to the rest of Magnoliales (Massoni et al., 2014; Qiu et al., 2006; Soltis et al., 2007), this placement is not consistent across all analyses (Magallón et al., 2015). Evidence suggests that Myristicaceae has a younger crown age than other magnoliid families, with estimates ranging between the Oligocene in youngest estimates (Massoni et al., 2015) to a stem origin in the Late Cretaceous in the most recent date phylogeny of all angiosperms (Magallón et al., 2015). Fossil evidence, in the form of the seed Myristicacarpum chandlerae in the London Clay formation that displays characteristics of crown Myrsiticaceae suggests that the family has existed since at least the early Eocene (Doyle et al., 2008). Myristicaceae is split into three major extant clades: the malouchoids, pycnanthoids, and myristicoids (Doyle et al., 2004). While most Neotropical members of this family are included in the myristicoids, Otoba is currently as part of the otherwise African pycnanthoid clade. Phylogenetic relationships within Myristicaceae remain relatively poorly resolved, however, with past studies including very limited taxon sampling (Doyle et al., 2004; Massoni et al., 2015).

Despite their ecological importance, there is no species-level phylogeny of Otoba to date and the lack of a robust family-level phylogenetic framework impedes placing it into a broader macroevolutionary context. We first perform a biogeographic analysis along the most densely sampled phylogeny of Myristicaceae to date, inferred from publicly available sequence data, to document the family's movement into the New World. Subsequently, in one of the first phylogenomic analyses that relies exclusively on DNA from herbarium specimens collected in the wet tropics, we resolve relationships within Otoba using the Angiosperms353 universal probeset. We use this phylogeny to determine the joint roles of ecological niche evolution and dispersal ability in driving biogeography in this ecologically important group.

\section{MATERIALS AND METHODS}

\section{Taxon Sampling}


Twenty accessions of Otoba representing nine (O. acuminata, O. cyclobasis, O. glycycarpa, $O$. gordoniifolia, $O$. gracilipes, $O$. latialata, $O$. novogranatensis, $O$. parvifolia, and $O$. vespertilio) of the ten accepted species and two undescribed species (Otoba sp. nov.) were sampled. All accessions came from herbarium specimens; voucher information may be found in Appendix S1 (see Supporting Information). Herbarium acronyms follow Index Herbariorum (Thiers, constantly updated: http://sweetgum.nybg.org/science/ih/). To serve as outgroups, data from the following transcriptomes available on 1KP project (Carpenter et al., 2019; One Thousand Plant Transcriptomes Initiative, 2019); <https://db.cngb.org/onekp/>) were gathered for Myristicaceae (Myristica fragrans), the broader Magnoniales (Magnolia maudiae, Annona muricata), and Laurales (Cassytha filiformis, Sassafras albidum, and Persea borbonia).

To put Otoba in a broader phylogenetic context, we also inferred a broader phylogeny of Otoba using publicly available DNA sequences. For this, we sampled plastid loci matK, rbcL, and ndhF from species of all species of Myristicaceae represented in GenBank, as well as outgroup Annonaceae, Magnoliaceae, Degeneriaceae, and Lauraceae (Appendix S2).

\section{DNA extraction, library prep, target enrichment, and sequencing}

$500 \mathrm{mg}$ of leaf tissue from herbarium specimens was homogenized using an MP Biomedicals FastPrep-24TM 5G. DNA extraction followed a modified sorbitol extraction protocol (Štorchová et al., 2000). DNA concentration was quantified using an Invitrogen Qubit 4 Fluorometer, and fragment size was assessed on a $1 \%$ agarose gel. For samples with a high concentration of large fragments (>800 bp), the DNA was sheared using a Bioruptor Pico (Diagenode Inc., Denville, New Jersey, United States) to obtain an average fragment size of $500 \mathrm{bp}$. Library preparation was carried out using KAPA Hyper Prep and HiFi HS Library Amplification kits (F. Hoffmann-La Roche AG, Basel, Switzerland) and with iTru i5 and i7 dual-indexing primers (BadDNA, University of Georgia, Athens, Georgia, United States). Library preparation with KAPA Hyper Prep followed the manufacturer's protocol (KR0961 - v8.20), except for the following modifications: reaction volumes were halved (i.e., $25 \mu \mathrm{L}$ starting reaction), and beadbased clean-ups were performed at $3 \mathrm{X}$ volume rather than $1 \mathrm{X}$ volume to preserve more small fragments from degraded samples. Library amplification reactions were performed at $50 \mu \mathrm{L}$. Target enrichment was carried out using the MyBaits Angiosperms353 universal probe set (Däicel Arbor Biosciences, Ann Arbor, MI; (Johnson et al., 2019) following the protocol outlined in (Hale et al., 2020). Twenty nanograms of unenriched DNA library was added to the cleaned, target enriched pool to increase the amount of off-target, chloroplast fragments in the sequencing library. DNA libraries were sent to Novogene Corporation Inc., (Sacramento, California, United States) for sequencing on an Illumina Hiseq 3000 platform with 150 bp pairedend reads.

\section{Sequence processing, assembly, and alignment}


Raw sequence reads were demultiplexed by Novogene. Adapter sequence removal and read trimming were performed using illumiprocessor v2.0.9 (Faircloth, 2016; Faircloth et al., 2012), a wrapper for trimmomatic v0.39 (Bolger et al., 2014). The default settings were used and reads with a minimum length of $40 \mathrm{bp}$ kept.

HybPiper v. 1.3.1 (Johnson et al., 2016) was used to assemble and extract target regions. Read mapping, contig assembly and coding sequence extraction were performed running the reads_first.py script. The intronerate.py script extracted introns and intergenic sequences flanking targeted exons. The retrieve_sequences.py script was run first with the "dna" argument to extract coding regions and subsequently with the "supercontig" argument to extract both coding and non $\square$ coding regions as a single concatenated sequence for each target gene. Individual genes were aligned using MAFFT v. 7.310 (Katoh \& Standley, 2013).

Alignments were visually inspected in AliView v. 1.18.1 (Larsson, 2014). Alignment errors were manually corrected and assembly errors, as well as areas that were difficult to align, were removed from individual alignments. Outgroup sequences were added to cleaned alignments and aligned using MUSCLE v.3.8.31 (Edgar, 2004) in AliView (Larsson, 2014). Summary statistics on gene alignments were obtained using AMAS (Borowiec, 2016), including length, missing data, and number of parsimony informative sites.

Off-target chloroplast reads were extracted using FastPlast v1.2.6 (https://zenodo.org/record/973887). For all samples there was insufficient data to produce a full plastome. The SPAdes-assembler built into FastPlast iteratively used k-mer lengths of 55, 87 , and 121. Assembled contigs from the iteration using k-mer length 87 were mapped to a reference plastome obtained from GenBank (Clark et al., 2016): Horsfieldia pandurifolia (GenBank accession number NC_042225.1). Once mapped, contigs were cleaned by eye to remove assembly errors before generating a consensus sequence. Consensus sequences for each sample were aligned visually against the Horsfieldia plastome. Sequences from plastomes of Annona muricata (MT742546.1), Cassytha filiformis (MF592986.1), Magnolia maudiae (MN990580.1), and an unverified plastome for Myristica yunnanensis (MK285565.1) were added as additional outgroups.

Plastid sequences from Myristicaceae from GenBank for whole-family phylogenetic analysis were aligned using MUSCLE in AliView.

\section{Phylogenetic analyses of Otoba}

Alignments for each locus were processed with trimAl (Capella-Gutiérrez \& Silla-Martínez, 2009), assigning a gap threshold of $15 \%$ or $20 \%$ to each column, depending on the number of taxa in the alignment. Thresholds were chosen to maintain columns with data for four or more individuals. A concatenated alignment of all nuclear and plastid data was analyzed in RAxML under the GTR model with optimization of substitution rates and site-specific evolutionary rates. RogueNaRok v.1.0 (Aberer et al., 2011) was subsequently used to identify individuals that 
negatively impacted phylogenetic inference. Individuals identified by RogueNaRok and or those with little data (total $\mathrm{bp}<1 \%$ of aligned length) were excluded from final analysis.

Divergence times were estimated on the inferred topology using penalized likelihood in treepl (Smith \& O'Meara, 2012). Crown ages from the literature (Magallón et al., 2015; Massoni et al., 2015) for Laurales + Magnoliales, Laurales, Magnoliales, and Myristicaceae were applied as secondary calibrations. Because (Massoni et al., 2015) presented five different calibration schemes, we used the average of their estimated ages as the mean age for our calibration. The youngest and oldest dates in the $95 \%$ confidence interval of any scheme across their different analyses were assigned as the minimum and maximum ages in our analysis. We performed an additional set of analyses that included a secondary calibration on the crown node of Otoba that corresponded to the $95 \%$ highest posterior density (HPD) of this node in the more densely sampled phylogeny of the entire Myristicaceae with calibrations derived from the same two sources (see below).

\section{Phylogenetic analysis of Myristicaceae}

We performed preliminary ML analyses on individual loci in RAxML. Sequences that systematically reduced support values were identified in RougeNaRok (i.e., RNR values >0.5) and subsequently removed. Updated alignments were then concatenated and used to jointly infer species relationships and divergence times in BEAST v2.3.6 (Bouckaert et al., 2019). We used PartitionFinder2 (Lanfear et al., 2017) to identify an appropriate partitioning scheme and model of molecular evolution for each partition. For each of two analyses, we assigned normally distributed priors nodes corresponding to the same calibration points used for dating in Otoba, with calibration points from both (Magallón et al., 2015) and (Massoni et al., 2015). For each analysis, we linked tree and clock models and set a lognormal clock prior. Eight runs each with four chains were allowed to progress for 10 million generations, sampling every 5,000 generations. Convergence was assessed using ESS values in Tracer v1.7.1 (Rambaut et al., 2018) with a cutoff value of 200. A maximum clade credibility tree was assembled in TreeAnnotator on the combined output from all runs after a $20 \%$ burnin was discarded..

\section{Biogeographic inference}

We modeled biogeographic movements using BioGeoBEARS (Massana et al., 2015; Matzke, 2014). For Otoba, movement both between Central and South America, as well as distribution on either side of the Andes were modeled along the Magallón et al. (2015) calibrated tree that included an additional calibration for the crown node of Otoba. Each species was coded for occurrence in (A) Central America, $(B)$ South America, or (AB) both. Species were also coded for their distribution on $(A)$ the western side of Andes, including the Darién gap and Central America or $(B)$ the eastern side of the Andes including western Amazonia. Six biogeographic models were tested; the DIVA-like model was selected for both reconstruction of 
continental movements and reconstruction of distribution around the Andes. A maximum of two ancestral areas was allowed for both analyses.

To put Otoba in a global context, we performed biogeographic analysis on the phylogeny of Myristicaceae calibrated with dates from Magallón et al. (2015). Outgroups, which had nonrepresentative sampling, were removed. The range of each species was coded as Asia (As), Africa (Af), or the Neotropics (N). Analyses were performed as above, with the DIVA-like model selected as best-fit.

\section{Environmental niche modeling and evolution}

Environmental niche models were generated for each of the species sampled Occurrence data were gathered from GBIF (gbif.org). Using the R package raster (Hijmans et al., 2015), the standard WorldClim 2.0 30s Bioclimatic variable layers (Fick \& Hijmans, 2017) and the WorldClim 2.1 30s elevation layer (https://www.worldclim.org/data/worldclim21.html) were stacked and clipped to the tropical latitudes of the Americas (extent = -120, -30, -23, 23). Variables were assessed for correlation in using R package ENMTools (Warren et al., 2019). Bioclimatic variables for diurnal range (BIO 2), isothermality (BIO 3), maximum temperature of warmest month (BIO 5), precipitation seasonality (BIO 15), precipitation of warmest quarter (BIO 18 ), and precipitation of coldest quarter (BIO 19) were chosen as minimally correlated variables for modeling. Generalized linear models were prepared for each species with ENMTools. Because phylogenetic results suggested that $O$. novogranatensis is not monophyletic, occurrences from Central America and South America were analyzed separately as $O$. novogranatensis_CA and $O$. novogranatensis_SA, respectively.

To quantify the multidimensional niche in Otoba, a phylogenetic principal components analysis of the average value of the 19 WorldClim bioclim variables using a correlation matrix was performed using the phyl.pca() command in phytools (Revell, 2012). Ancestral state reconstruction of the first three principal components was performed with the contMap() function in phytools (Revell, 2012). We then used Orstein-Uhlenbeck models in the I1ou R package (Khabbazian et al., 2016) to detect shifts to different climatic niches in the absence of an a priori hypothesis about their location or convergent regimes. We searched for shifts in the first three climate principal components on the concatenated Otoba topology, and assessed support for the shifts identified via a bootstrap analysis with 100 replicates.

\section{RESULTS}

Summary statistics of data assembly - The number of input read pairs, surviving paired reads, surviving unpaired reads, and dropped reads from read trimming as well as the number of Angiosperm353 loci captured, average sequence length, number of ungapped basepairs of chloroplast DNA (cpDNA) for each sample, collection year at the collection locality are listed in Appendix S3. A heatmap of the percent of the reference protein length recovered for each sample at each locus can be found in Appendix S4. Due to large amounts of missing data in 
both nuclear and chloroplast regions, the following samples were excluded from all phylogenetic analyses: O. gracilipes_DC884, O. novogranatensis_EB500, O. parvifolia_DN9151, O. sp. nov._RC5752, O. sp. nov._JP16902, and O. vespertilio. Overall, we were able to include 7 of the 10 described species of Otoba in phylogenetic analyses.

Hybrid enriched target sequence capture success was variable across samples. Half of the 20 samples submitted for sequencing recovered fewer than 10 Angiosperm353 loci; only 3 samples recovered more than 100 loci (Appendix S3). Success in gathering off-target plastid data did not necessarily correspond to success in capturing nuclear loci. For example, the sample with the most nuclear data- O. novogranatensis_WS36336 with 217 of the 353 targeted loci- did not recover useful chloroplast data. On the other hand, nearly half of the chloroplast genome was obtained for 0 . parvifolia_MS1182, despite recovering only 6 nuclear loci.

\section{Phylogenetic analyses of Otoba}

We found support for the monophyly of Otoba within Myristicaceae (Bootstrap support [BP]= 100; Fig. 2) and for three subclades of Otoba (Fig. 2). The first subclade ( $B P=100)$, corresponding to South American accessions of $O$. novogranatensis, is sister to the rest of Otoba $(\mathrm{BP}=100)$. The second subclade includes a paraphyletic $O$. parvifolia and a single accession of $O$. glycycarpa $(\mathrm{BP}=75)$, while the third comprises $O$. acuminata, O. cylclobasis, $O$. gordoniifolia, O. latialata, and O. novogranatensis from Central America $(B P=100)$. Within the third subclade, we find that $O$. cyclobasis is sister to the remaining species, with $O$. gordoniifolia and $O$. latilata forming a sister pair and $O$. acuminata sister to Central American accessions of O. novogranatensis.

Divergence times in Otoba estimated from different calibrations schemes were similar between calibrations from Massoni et al. (2015) and Magallón et al. (2015), but differed if an additional calibration derived from our BEAST analyses of Myristicaceae were used (Appendix S5). All estimates support the radiation of Otoba in the Miocene (Appendix S5). The crown age for Otoba based only on calibrations from Magallón et al. (2015) is estimated to be 7.32 Ma and based only on (Massoni et al., 2015) are 8.23 Ma. These dates were pushed back when the additional calibration was added, to $12.48 \mathrm{Ma}$ with the Magallón et al. (2015) calibrations and 13.74 Ma with those from Massoni et al. (2015). 


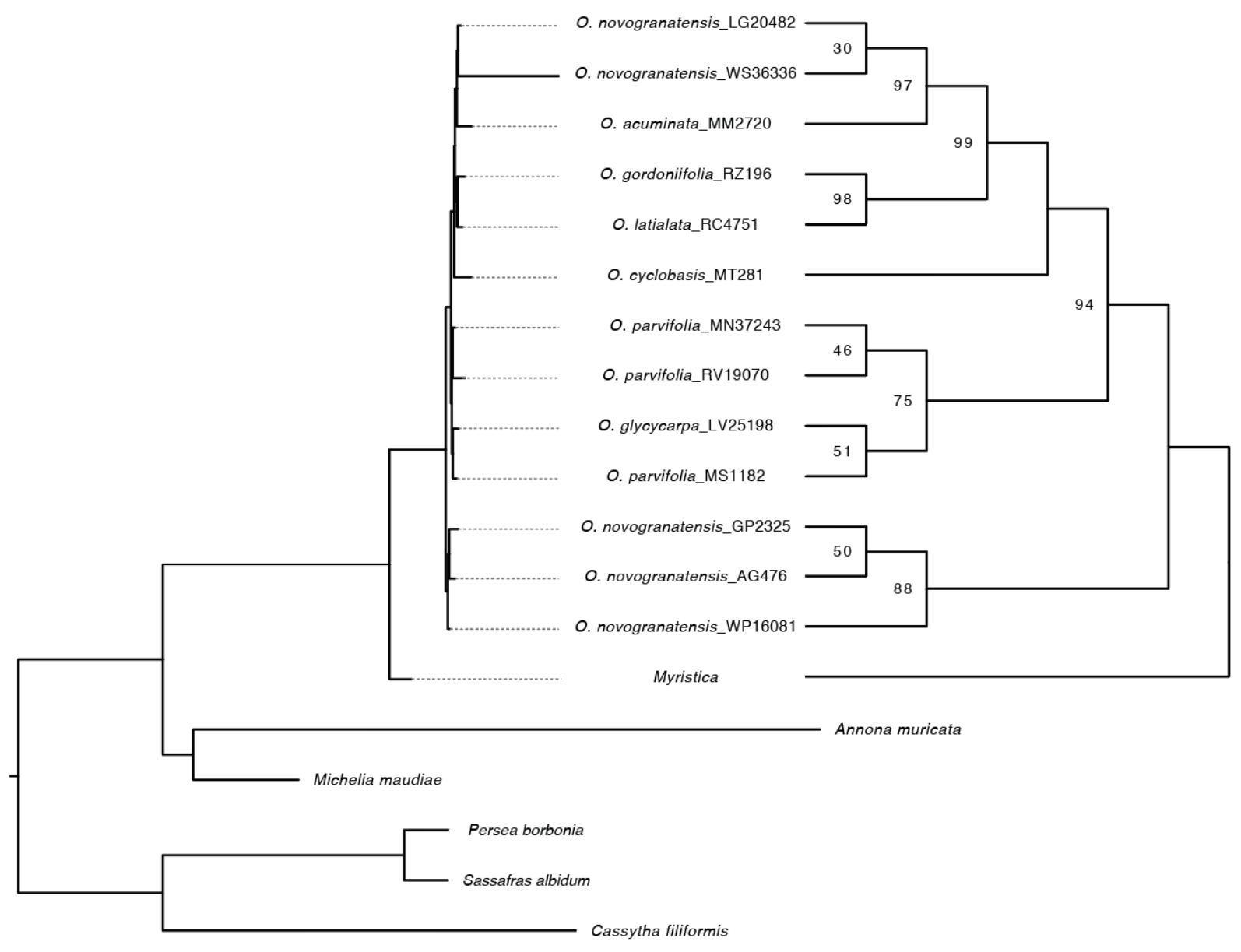

Figure 2. Results of ML analyses of concatenated chloroplast and nuclear data. The tree on the right shows branch lengths; the cladogram on the left shows the branching pattern for the ingroup + Mryistica and support values at nodes with $<100$ bootstrap support (all outgroup relationships were fully supported).

\section{Phylogenetic analyses of Myristicaceae}

The monophyly of Myristicaceae is well-supported ( $\mathrm{PP}=1.0$ with Massoni calibrations/1.0 with Magallón calibrations), as is the monophyly of four major subclades that correspond to broad geographic regions (Fig. 3; Appendices S6-7). An African subclade (PP=1.0/1.0), comprising the genera Pycnanthus, Coelocaryon, Staudia, Brochoneura, Maulotchia, and Cephalosphaera, is sister to the rest of the family. The first of two Asian subclades ( $\mathrm{PP}=0.64 / 0.66)$ comprises the genus Horsfieldia and is sister to the second Asian subclade + the Neotropical subclade. The second Asian subclade ( $P P=0.84 / 0.84$ ) includes three genera, each found to be monophyletic in 
our sampling: Knema ( $\mathrm{PP}=1.0 / 1.0)$, Myristica ( $\mathrm{PP}=1.0 / 1.0)$, and Gymnacanthera ( $\mathrm{PP}=1.0 / 1.0)$. Finally, the Neotropical subclade $(\mathrm{PP}=0.99 / 0.99)$ includes all Neotropical genera. Within it, Otoba $(\mathrm{PP}=1.0 / 1.0)$ and Virola $(\mathrm{PP}=1.0 / 1.0)$ are subsequently sister to the remaining genera, with Iryanthera $(\mathrm{PP}=1.0 / 1.0)$ forming a clade sister to a poorly supported Composoneura + Osteophloeum (PP=0.47/0.45).

As within Otoba, we find that the Massoni et al. calibration scheme gives slightly younger ages (Appendices S6-7). Crown Myristicaceae is estimated to have originated in the Eocene in both analyses, at 40.77Ma [26.9-54.7] with the Massoni et al. calibrations and at 52.02Ma [26.25-78.91] with the Magallón et al. calibrations. The crown Neotropical subclade originated in the Paleocene in both analyses (26.45Ma [16.28-38.27] / 30.77Ma [16.77-49.07]). Ages inferred for Otoba in the Myristicaceae-wide dataset are older than in the Otoba-specific analyses (Appendix S5), but still within the Miocene (11.41 Ma [2.81-21.62] / 13.08 Ma [2.1825.74]). 
bioRxiv preprint doi: https://doi.org/10.1101/2020.10.02.324368; this version posted February 26, 2021. The copyright holder for this preprint (which was not certified by peer review) is the author/funder, who has granted bioRxiv a license to display the preprint in perpetuity. It is made available under aCC-BY-NC 4.0 International license.

Frost et al., page 15

Biogeography of Otoba and Myristicaceae

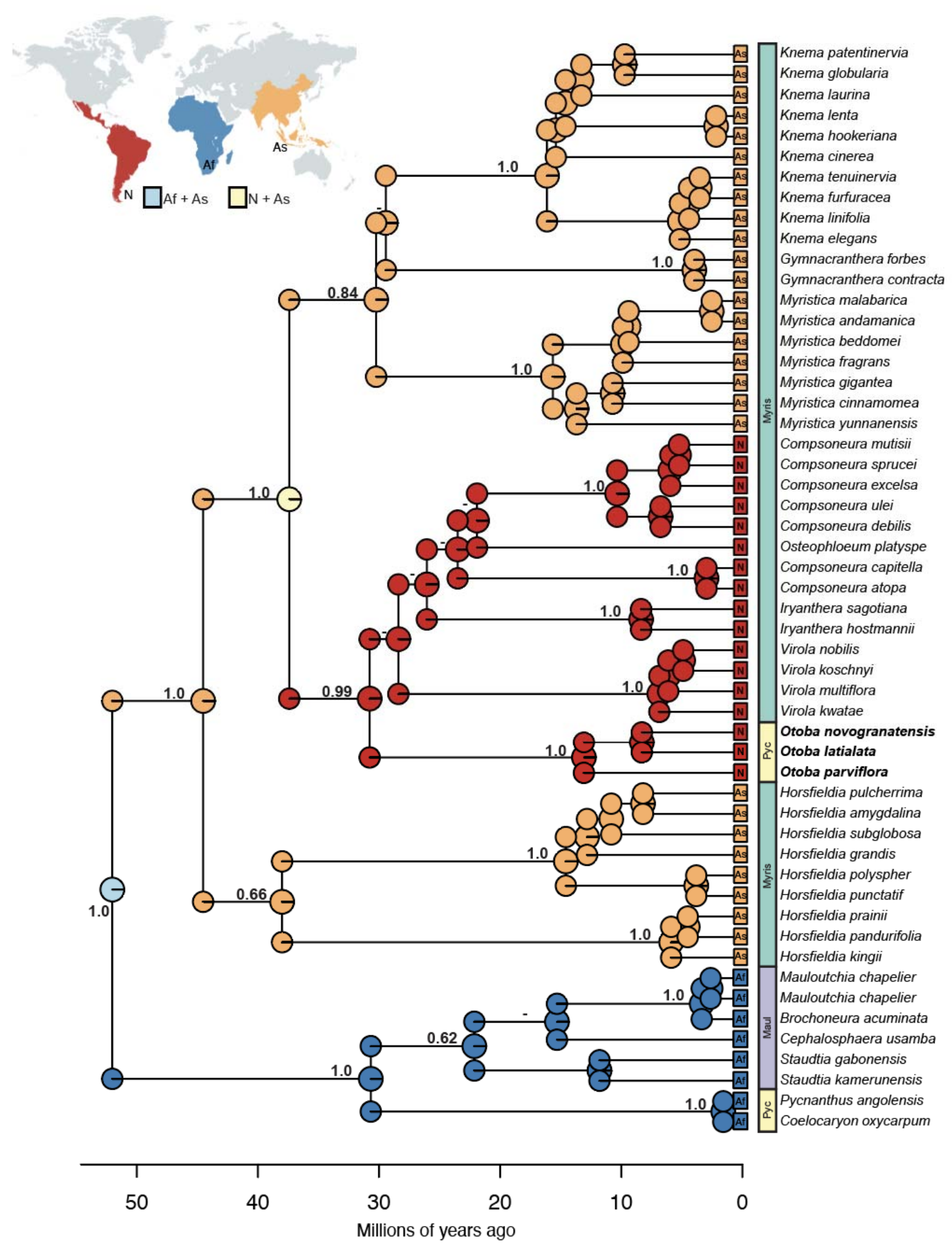

Fig. 3. Time-calibrated plastid phylogeny of Myristicaceae depicting global biogeography. The phylogeny represents the maximum clade credibility tree of a BEAST2 analysis using calibration points from Magallón et al (2015). Values at nodes represent posterior probabilities, with dashes representing <50 PP; support for relationships below genus level are not included except in instances of deep splits with a genus, but are available in Appendix S6, as are the 95\% HPD for the date at each node. Ancestral area reconstructions as inferred by the best-fit DIVA-like model in BioGeoBEARS are depicted in pie charts at each node, with colors corresponding to the areas in the map at top left (dark blue= Africa; orange $=$ Asia; red= Neotropics; yellow = both Neotropics and Asia; light blue = both Africa and Asia). The previously understood major clades of Myristicaceae from Sauquet et al. (2003) are indicated by the colored bars at the right of the phylogeny (yellow = pycnanthoids; purple = mauloutchioids; green = myristicoids). 


\section{Biogeographic Reconstruction}

We find that Myristicaceae, as a whole, originated in the Old World tropics, with a broad range spanning both the Asian and African tropics. It expanded its range into the Neotropics once, between 37.41-30.77 Ma via an ancestor with a broad range that spanned the Americas and Asia (Fig. 3). This resulted in in situ diversification leading to five endemic extant Neotropical genera, including Otoba. The western side of the Andes is inferred to be the ancestral area for Otoba (Fig. 4). Dispersal to the eastern side of the Andes best explains the divergence of the O. glycycarpa-O. parvifolia clade (Fig. 4B). In the western-Andean clade including $O$. acuminata and $O$. cyclobasis, a South American ancestor is inferred with expansion into Central America via widespread ancestors (Fig. 4A).
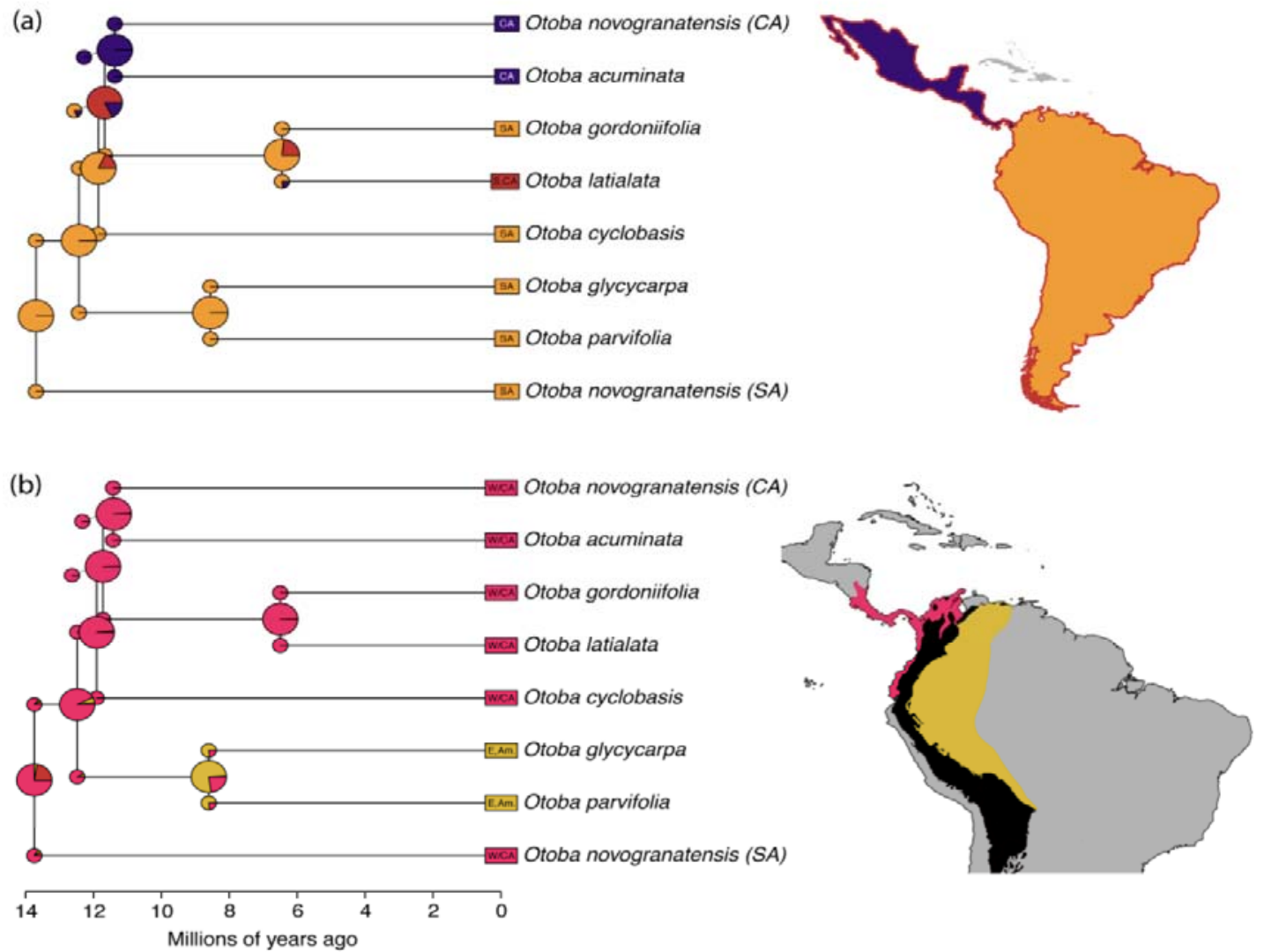

Figure 4. Ancestral area reconstructions in Otoba for $(A)$ Central America versus South America and $(B)$ western Andes and Central America versus eastern Andes and the Amazon. Pie charts at nodes display the probability that the ancestor occupied a given range. Maps to the left of each tree are color coded to correspond with the geographic areas coded on the tree. In (A), orange = South America, purple = Central America, and red $=$ both Central and South America; the distribution of each species in Central and/or South America is additionally reflected in the color-coded boxes at the tips of the tree. In (B), pink = western Andes and Central America, and mustard = eastern Andes and the Amazon; the Andes are represented in black.

\section{Niche Modeling and Evolution}


Visualizations of GLM models can be found in Fig. 5a and average values for each BIOCLIM variable and elevation in Appendix S8. The first three principal components from our phylogenetic PCA of BIOCLIM variables describe $91.7 \%$ of the variation in climatic preferences. The most important loadings for pPC1, which describes $57.9 \%$ of the variation, are mean temperature of the driest quarter (BIO9), mean temperature of the coldest quarter (BIO11), mean annual temperature (BIO1), minimum temperature of the coldest month (BIO6), and mean temperature of the warmest quarter (BIO10), making it a useful proxy for temperature regime (Appendix S9). The most important loadings for pPC2, which describes $21.3 \%$ of the variation, are temperature seasonality (BIO4) and isothermality (BIO3), making it a useful proxy for temperature stability (Appendix S9). Finally, the most important loadings for pPC3, which describes $12.5 \%$ of the variation, are mean diurnal temperature range (BIO2), annual temperature range (BIO7), and precipitation seasonality (Appendix S9). We observed a broad occupation of climate in phylomorphospace (Fig $5 \mathrm{c}$ ). Of particular note, the sister species $O$. latialata (native to the Chocó region) and O. gordoniifolia (an Andean montane species) are the two most distinct species, falling on extreme ends of pPC1 and also differing substantially in pPC2. Further, the western Amazonian sister pair O. glycycarpa and O. parvifolia, while relatively similar to each other, form a separate cluster in phylomorphospace, largely due to their extreme value of pPC3.

Orstein-Uhlenbeck models in I1ou identify four highly supported niche shifts in our analysis of pPC1-3 (Fig. 5b). These correspond to 1) O. glycycarpa + O. parvifolia (PP=99), which experienced a shift to increased temperature extremes and decreased precipitation seasonality in $\mathrm{pPC} 3$; 2) $O$. latialata ( $\mathrm{PP}=98$ ), which experienced a shift to warmer temperatures ( $\mathrm{pPC1}$ ) and increased temperature stability (pPC2); O. gordoniifolia ( $\mathrm{PP}=98)$, which experienced a shift towards cooler temperatures ( $\mathrm{PPC} 1$ ); and $O$. acuminata $+O$. novogranatensis ( $\mathrm{PP}=92)$, which experienced a minor increase in temperature ( $\mathrm{pPC} 1)$ and a larger shift towards decreased temperature stability (pPC2). These shifts mirror results from ancestral state reconstruction of individual pPCs (Appendix S10), and are often accompanied by shifts in biogeography (Fig. 4,5). 


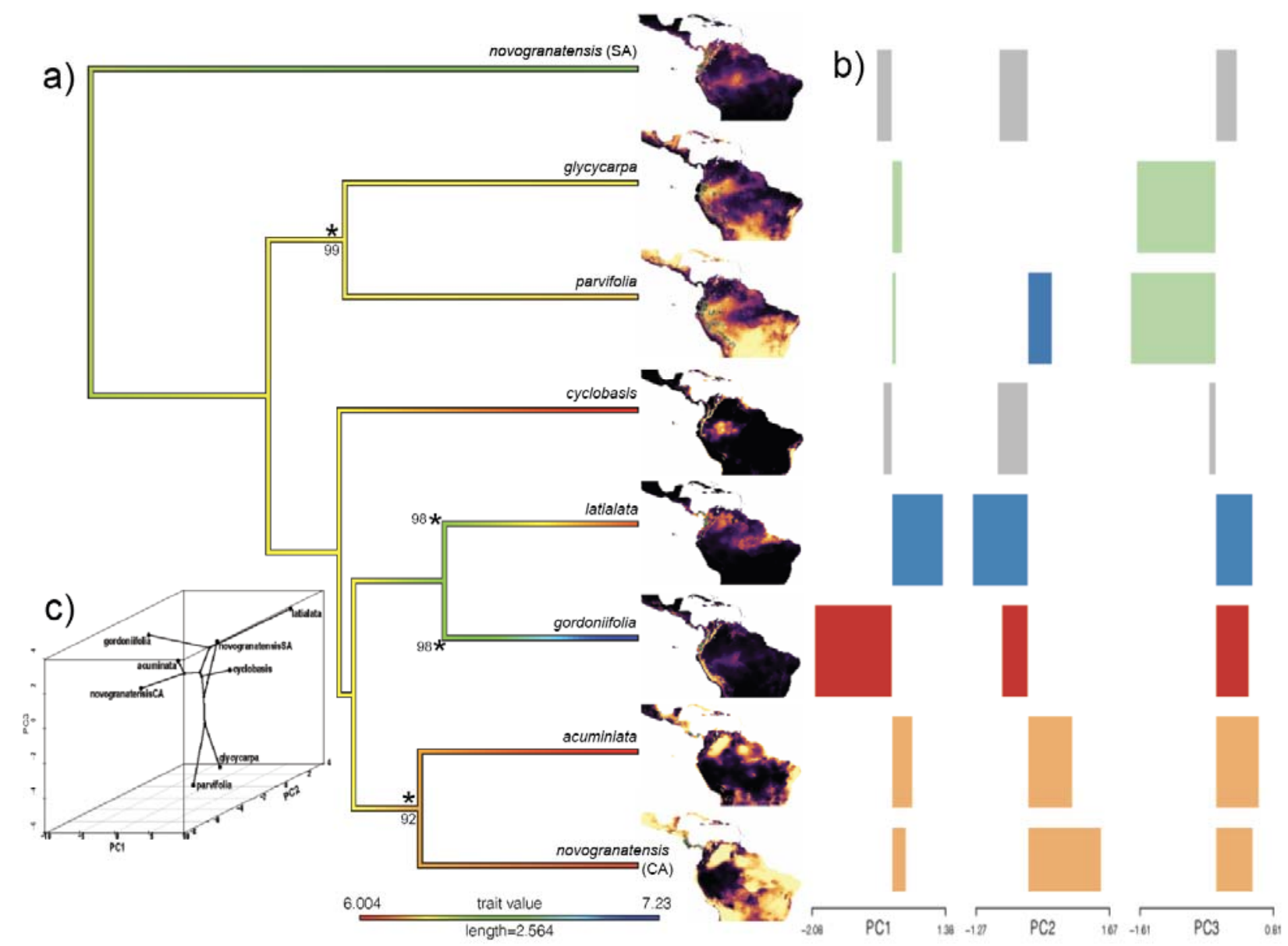

Fig. 5. Niche evolution in Otoba is dynamic. A) Ancestral state reconstruction of average elevation ( $\mathrm{m}$ ) in Otoba demonstrates the wide range of elevational preferences among species, ranging from $404 \mathrm{~m}$ in O. acuminata to $1380 \mathrm{~m}$ in $\mathrm{O}$. gordoniifolia. At right, species distributions modeled in Maxent demonstrate the variation in potential niche suitability in the Neotropics. B) Orstein-Uhlenbeck models implement in I1ou infer four shifts in climate space, denoted by asterisk at node with bootstrap value, corresponding to the western Amazonia clade; O. latialata; O. gordoniifolia; and a Central American clade comprising $O$. acuminata and $O$. novogranatensis (CA). C) Phylomorphospace of phylogenetic PCA of BIOCLIM variables.

\section{DISCUSSION}

\section{Phylogeny of Otoba and the broader Myristicaceae}

Our plastid phylogeny of Myristicaceae, which combined publicly available plastid sequences supplemented by the same loci from our target capture data, is the most densely sampled phylogeny of the family to date (Fig. 3). At the deepest temporal scale, our results are broadly similar to past studies (Doyle et al., 2004; Sauquet et al., 2003): we resolve an African (including Malagasy) subclade that includes the mauloutchoids and African pycnanthoids as sister to the Asian and American myristicoid clade. However, there are some key differences. Notably, we find that Otoba is part of a newly resolved Neotropical subclade of myristicoids, and not sister to the African pycnanthoid genera Pycnanthus and Coelocaryon, as in (Sauquet et al., 
2003). This result has important biogeographic implications, discussed below, and suggests that informal clade names previously applied to Myristicaceae are in need of redefinition. Further, resolution within the myristicoid clade is improved. We find support for three subclades: the Asian genus Horsfieldia, the remaining Asian genera, and all Neotropical genera, with Horsfieldia sister to the remaining two. This updated phylogeny provides a useful framework for subsequent macroevolutionary research in Myristicaceae.

While our family-wide analysis found that Otoba is sister to the remaining Neotropical genera, our phylogenomic analysis resolved relationships within the genus. This represents the first phylogeny of Otoba to date, and the first phylogenetic analysis to include more than a single species (Doyle et al., 2004; Massoni et al., 2015; Sauquet et al., 2003). Phylogenetic results within Otoba point to the need for future phylogeographic and taxonomic study. We find strong evidence for polyphyly of the widespread O. novogranatensis (Fig. 2). In this species, two distinct lineages correspond to South American and Central American accessions, highlighting a need for future taxonomic research. A preliminary revision of herbarium specimens of this wellcollected species reveal that South American accessions differ from those from Central America in their thicker pericarp, pubescent ovaries, anthers that can be unfused to the base, and generally white arils (de Candolle, 1856; Jaramillo et al., 2004; Jaramillo-Vivanco \& Balslev, 2020).

\section{Challenges of herbarium phylogenomics from wet tropical specimens}

Our study is among the first exclusively herbariomic datasets generated via target sequence capture for a wet tropical genus. Even high efficiency target capture will fail when DNA is low quality, as is typical in herbarium specimens collected in these ecosystems (Brewer et al., 2019), especially when they are preserved in ethanol ahead of drying (Särkinen, Staats, et al., 2012) - a common scenario for Otoba, and likely universal in the herbarium specimens that we sampled. It is thus not surprising that not all of the samples that we attempted to include in our phylogeny generated useful sequences; we had to remove some completely due to poor quality reads and apparent contamination following visual inspection of alignments. In other cases, we were able to extract a handful of useful loci, but at a much lower quality than the majority of our included species.

Universal probesets result in different quality datasets depending on phylogenetic scale and distance from species used in their design (Hutter et al., 2019). While we were able to infer relationships in Otoba using Angiosperms353 loci, there was very limited variation across our dataset (i.e., the proportion of variable sites in concatenated target loci was 0.285 ). It is likely that a custom probe kit designed for Otoba and close relatives would have outperformed the Angiosperms353 loci, either alone or in combination (Jantzen et al., 2020), especially as only a single species of Myristicaceae was used in the development of Angiosperms353 loci (Johnson et al., 2019). However, developing such custom loci is predicated on the existence of genomic resources, either pre-existing or newly generated, which would have been difficult for Otoba. 
While the number of angiosperms genomic resources is constantly growing (One Thousand Plant Transcriptomes Initiative, 2019), there are still no transcriptomes or nuclear genomes available for Otoba and data is limited for Myristicaceae overall: there is a single transcriptome available in the 1KP database (nutmeg, Myristica fragrans) and no other genomic resources. Because this scenario is common- especially in tropical plant groups, which tend to be understudied (Goodwin et al., 2015) — the universal utility and subsequent promise of assembling a standardized set of loci across analyses is desirable.

\section{Biogeography of Myristicaceae is marked by relatively few major movements}

As a whole, Myristicaceae have a surprisingly simple biogeographic history. At a continental scale, we infer fewer major biogeographical events than inferred than previously postulated (Doyle et al., 2004): one range expansion and two range contractions (Fig. 3). The relatively young age of Myristicaceae precludes a role of a Laurasian ancestor in the formation of its tropical disjunctions, contrasting with many of its relatives in Magnoliales, including Magnoliaceae (Azuma et al., 2001). Instead, we find that from a widespread common ancestor in the eastern hemisphere during the early Eocene, distinct lineages became restricted to Africa and Asia by the mid-Eocene. A subsequent lineage expansion to include the Neotropics occurred during the late Eocene-Oligocene, eventually giving rise to all extant Neotropical Myristicaceae, which are embedded within an otherwise Asian clade.

The Oligocene timing of Myristicaceae's amphi-Pacific disjunct is consistent with the boreotropics hypothesis (Wolfe, 1975). This is the scenario in which plant lineages with widespread distributions in the warm, wet conditions of the Northern Hemisphere in the Late Paleocene-Eocene were disrupted by climatic cooling in Oligocene, resulting in climate-driven vicariance (Lavin \& Luckow, 1993). Fossil evidence is further consistent with a boreotropical distribution for Myristicaceae. This includes the occurrence of Myristicacarpum chandlerae, which shares morphological traits with both Old World and New World taxa, in the early Eocene of the London Clay flora (Doyle et al., 2008), as well as leaves in the middle to late Eocene of the Alaska Gulf (Wolfe, 1977). Support for a potential role of range expansion over a continental plates in close proximity is further bolstered by lack of long-distance dispersal events in the history of the family, as well as the presence of large seeds for which long-distance dispersal is improbable. However, it is impossible to rule out long-distance dispersal over water without additional fossil evidence. Similar intercontinental, amphi-Pacific tropical disjunctions with documented or likely occurrence in the Boreotropics are seen in Annonaceae (Thomas et al., 2017; Xue et al., 2018), Melastomataceae (Morley \& Dick, 2003), Araliaceae (Valcárcel \& Wen, 2019), and other groups.

Finally, Otoba is strongly supported as an in situ radiation within a larger Neotropical clade. Contrasting with previous studies with more limited taxon sampling (Doyle et al., 2004), our updated phylogenetic and biogeographic results demonstrate that intercontinental longdistance dispersal does not need to be invoked to explain the origin of Otoba. 


\section{Landscape change, ecological niche evolution, and dispersal limitation interact to drive biogeography in Otoba}

The relatively stable global biogeography of Myristicaceae contrasts with the dynamic history of Otoba within the Neotropics. The complex geological history of the Neotropics, including the rapid uplift of the Andes and the closure of the Isthmus of Panama (Hoorn et al., 2010), is known to have had a dramatic impact on the evolution of its biota (Antonelli et al., 2009; Bacon et al., 2015; Hughes et al., 2006). We find evidence that both the uplift of the Andes and closure of the Isthmus of Panama have left signatures on the biogeographic history of Otoba.

At the time of origin of Neotropical Myristicaceae, a broad distribution across the northern Neotropics would have been facilitated by a more-or-less contiguous swathe of lowland rainforest and the low height of the Andes, including multiple low elevation gaps (Hoorn et al., 2010). However, by the time that crown Otoba originated in the late Miocene to early Pliocene, the genus was restricted to the western side of the Andes. (Fig. 4), an ancestral range shared with relatively few other Neotropical tree groups, including a clade of Annonaceae (Pirie et al., 2018). By this time, the northern Andes had gained approximately half their elevation (Garzione et al. 2017) and analogs to modern montane cloud forests had formed (Hughes, 2016; Martínez et al., 2020). Thus, even though they had not yet reached their full height, the Andes would have represented a significant barrier to dispersal for low- to-mid-elevation groups like Otoba due to the lack of appropriate habitat at high elevation. We find evidence for the Andes structuring biogeography in Otoba, with species and subclades occurring on only one slope of the mountain chain. A movement to the eastern slope occurred only once in Otoba at ca. $9 \mathrm{Ma}$, resulting in an eastern Andean/Amazonian clade comprising the two widespread species $O$. parvifolia and O. glycycarpa. This movement could be explained by either a dispersal across the Andes or a vicariance scenario involving the final uplift of the Mérida cordillera in Venezuela.

Movement between Central and South America is more dynamic than across the Andes in Otoba. This is not surprising as the Isthmus of Panamá was either formed (Bacon et al., 2015; Montes et al., 2012) or in the process of forming (O'Dea et al., 2016) when the genus originated, providing a land connection of appropriate habitat type that could facilitate northward movement. From an ancestral range of South America, a range expansion to include Central America is inferred for the most recent common ancestor of $O$. acuminata, $O$. novogranatensis (CA), O. gordoniifolia, and O. latialata in the late Miocene (Fig. 4). Otoba acuminata and Central American $O$. novogranatensis subsequently became restricted to Central America, while $O$. latilata has a widespread distribution in the Chocó-Darién moist forest from Colombia to Panama. It is possible that the common ancestor of this subclade may have inhabited a similar distribution to $O$. latialata. If this is the case, it may represent subset sympatry-when one daughter lineage inherits the ancestral range and the other daughter(s) inherit a portion of the ancestral range (Ree et al., 2005). An additional Central American species, O. vespertilio, was 
not included in our phylogenetic analysis due to poor data quality (Table 1; Appendix S3), but morphological evidence suggests this species likely represents an independent colonization of Central America (Santamaría-Aguilar et al., 2019). These migrations occurred within the last 10 million years, a time-frame that supports the role of the closure of the Isthmus of Panama (Montes et al., 2012; Bacon et al., 2013).

The limited movement of Otoba is likely explained by poor dispersal ability- a pattern echoed across the phylogeny of Myristicaceae, in which long-distance dispersal played little to no role in its current distribution (Fig 3). Otoba's relatively large seeds, which are dispersed birds, primates, and bats (Giraldo et al., 2007; Melo et al., 2009; Nuñez-Iturri \& Howe, 2007; Santamaría-Aguilar et al., 2019), make dispersal events over water barriers or large stretches of unsuitable terrestrial habitat uncommon compared to groups that are dispersed by wind (PérezEscobar et al., 2017) or migratory passerine birds (Nathan et al., 2008). It is further documented that dispersal ability in tropical trees is known to be negatively impacted by seed size (MullerLandau et al., 2008). On a continental scale and over evolutionary time, this has resulted in remarkably few long distance biogeographic movements. Otoba's migration into Central America was likely facilitated by the continuous land bridge of suitable habitat following the closure of the Isthmus of Panama, while cold high-elevation habitats likely prevented more frequent traversing of the Andes. Further supporting the role of low dispersal ability in the biogeography of Otoba, the genus does not occupy all of the suitable habitat it presumably could based on comparison of distributions of extant species ranges and species niche models (Fig. 5), including the Atlantic coast forest in Brazil and Caribbean islands. It may also explain why, unlike many of the most abundant taxa in lowland rainforests in the northern Neotropics (Bemmels et al., 2018), individual Otoba species are restricted to a single side of the Andes. At a local scale, dispersal limitation is observed in Otoba parvifolia, whose seeds are dispersed at low frequency, typically over short distances (Terborgh et al., 2011). However, high levels of seed-set, both in closed canopy forests and in treefall gaps, may make Otoba an effective colonizer of new habitats once they colonize a new region (Myster, 2020).

Despite relatively few major biogeographical movements, Otoba occurs in many habitat types, spanning a large temperature differential and including areas that are both completely aseasonal (e.g., O. latialata) and those with fairly well-defined seasons (e.g., Central American taxa) (Appendix S8). Labile niche evolution demonstrated by Otoba (Fig. 5) likely facilitates its establishment in new environments upon expansion or dispersal into new habitats - and, in fact, all biogeographic movements that we infer in Otoba also correspond with environmental niche shifts. This includes a shift towards broader temperature range and decreased precipitation seasonality tolerance following dispersal into the western Amazon and towards higher temperature fluctuations in the more seasonal environments of Central America upon expansion via the Isthmus of Panama. The greatest example of niche evolution in Otoba is the sister pair $O$. gordoniifolia, which is restricted to mid-elevations of the Andes and adapted to the coolest temperature in the genus, and the Chocoan $O$. latialata, which is adapted to the 
warmest temperatures in the genus (Fig. 5). These results suggest that Otoba is more constrained by movement into a new area than the ability to adapt to a new environment upon establishment. There are, however, obvious limits - Otoba is not found in high-elevation or very arid habitats, even when they are proximate to their current range. Like many other wet tropical trees (Esquivel-Muelbert et al., 2017), their absence in arid areas is likely due to physiological constraints in the face of drought, while freezing tolerance is an additional important constraint in high elevation grasslands (Koehler et al., 2012).

Conclusion - In Otoba, an ecologically dominant genus from a plant family in which long-distance dispersal is rare to non-existent, adaptation to new niches is much more common than major biogeographic movements into pre-adapted environments (Edwards \& Donoghue, 2013). This adds to a growing body of literature demonstrating that dispersal-driven niche evolution following movement from geographically proximal regions is key to the assembly of the Neotropical biota: large portions of its characteristic biomes, including the Amazon (Antonelli et al., 2018) and cerrado (Simon et al., 2009), are composed of local migrants with ancestors from different environments in close geographic proximity. A notable exception are montane environments, including low- to mid-elevation environments where some species of Otoba occur (Linan et al., 2021), as well as high elevation grasslands where it and other Myristicaceae are absent (Hughes \& Eastwood, 2006). This points towards an interaction of idiosyncratic cladebased traits interactions with steep environmental gradients driving patterns of plant distributions in the Neotropics.

\section{Data Availability Statement}

Illumina reads will be submitted to the NCBI Sequence Read Archive (SRA) and all other data formats (tree files, alignments, character matrices, etc.) will be uploaded on the Dryad Digital Repository and made available upon publication. 


\section{Literature Cited}

Aberer, A. J., Krompaß, D., \& Stamatakis, A. (2011). RogueNaRok: An efficient and exact algorithm for rogue taxon identification. Heidelberg Institute for Theoretical Studies:

Exelixis-RRDR-2011--10. http://sco.h-its.org/exelixis/pubs/Exelixis-RRDR-2011-10.pdf

Alrashedy, N. A., \& Molina, J. (2016). The ethnobotany of psychoactive plant use: a phylogenetic perspective. PeerJ, 4, e2546.

Antonelli, A., Nylander, J. A. A., Persson, C., \& Sanmartín, I. (2009). Tracing the impact of the Andean uplift on Neotropical plant evolution. Proceedings of the National Academy of Sciences of the United States of America, 106(24), 9749-9754.

Antonelli, A., Zizka, A., Carvalho, F. A., Scharn, R., Bacon, C. D., Silvestro, D., \& Condamine, F. L. (2018). Amazonia is the primary source of Neotropical biodiversity. Proceedings of the National Academy of Sciences of the United States of America, 115(23), 6034-6039.

Armstrong, J. E., \& Irvine, A. K. (1989). Floral biology of Myristica insipida (Myristicaceae), a distinctive beetle pollination syndrome. American Journal of Botany, 76(1), 86-94.

Armstrong, J. E., \& Tucker, S. C. (1986). Floral development in Myristica. American Journal of Botany, 73(8), 1131-1143.

Azuma, H., García-Franco, J. G., Rico-Gray, V., \& Thien, L. B. (2001). Molecular phylogeny of the Magnoliaceae: the biogeography of tropical and temperate disjunctions. American Journal of Botany, 88(12), 2275-2285.

Bacon, C. D., Silvestro, D., Jaramillo, C., Smith, B. T., Chakrabarty, P., \& Antonelli, A. (2015). Biological evidence supports an early and complex emergence of the Isthmus of Panama. Proceedings of the National Academy of Sciences of the United States of America, 112(19), 6110-6115.

Bemmels, J. B., Wright, S. J., Garwood, N. C., Queenborough, S. A., Valencia, R., \& Dick, C. W. (2018). Filter-dispersal assembly of lowland Neotropical rainforests across the Andes. Ecography, 41(11), 1763-1775.

Bolger, A. M., Lohse, M., \& Usadel, B. (2014). Trimmomatic: a flexible trimmer for Illumina sequence data. Bioinformatics , 30(15), 2114-2120.

Borowiec, M. L. (2016). AMAS: a fast tool for alignment manipulation and computing of summary statistics. PeerJ, 4, e1660.

Bouckaert, R., Vaughan, T. G., Barido-Sottani, J., Duchêne, S., Fourment, M., Gavryushkina, A., Heled, J., Jones, G., Kühnert, D., De Maio, N., Matschiner, M., Mendes, F. K., Müller, N. F., Ogilvie, H. A., du Plessis, L., Popinga, A., Rambaut, A., Rasmussen, D., Siveroni, I., ... Drummond, A. J. (2019). BEAST 2.5: An advanced software platform for Bayesian evolutionary analysis. PLoS Computational Biology, 15(4), e1006650.

Brewer, G. E., Clarkson, J. J., Maurin, O., Zuntini, A. R., Barber, V., Bellot, S., Biggs, N., Cowan, R. S., Davies, N. M. J., Dodsworth, S., Edwards, S. L., Eiserhardt, W. L., Epitawalage, N., Frisby, S., Grall, A., Kersey, P. J., Pokorny, L., Leitch, I. J., Forest, F., \& Baker, W. J. (2019). Factors affecting targeted sequencing of 353 nuclear genes from 
herbarium specimens spanning the diversity of angiosperms. Frontiers in Plant Science, 10, 1102.

Capella-Gutiérrez, S., \& Silla-Martínez, J. M. (2009). trimAl: a tool for automated alignment trimming in large-scale phylogenetic analyses. Bioinformatics, 25(15), 1972-1973.

Carpenter, E. J., Matasci, N., Ayyampalayam, S., Wu, S., Sun, J., Yu, J., Jimenez Vieira, F. R., Bowler, C., Dorrell, R. G., Gitzendanner, M. A., Li, L., Du, W., K Ullrich, K., Wickett, N. J., Barkmann, T. J., Barker, M. S., Leebens-Mack, J. H., \& Wong, G. K.-S. (2019). Access to RNA-sequencing data from 1,173 plant species: The 1000 Plant transcriptomes initiative (1KP). GigaScience, 8(10). https://doi.org/10.1093/gigascience/giz126

Clark, K., Karsch-Mizrachi, I., Lipman, D. J., Ostell, J., \& Sayers, E. W. (2016). GenBank. Nucleic Acids Research, 44(D1), D67-D72.

de Candolle, A. (1856). Ordo CLXIII. Myristicaceae. Prodromus Systematis Naturalis Regni Vegetabilis, 14, 189-208.

Dick, C. W., Lewis, S. L., Maslin, M., \& Bermingham, E. (2012). Neogene origins and implied warmth tolerance of Amazon tree species. Ecology and Evolution, 3(1), 162-169.

Donoghue, M. J. (2008). Colloquium paper: a phylogenetic perspective on the distribution of plant diversity. Proceedings of the National Academy of Sciences of the United States of America, 105 Suppl 1, 11549-11555.

Donoghue, M. J., \& Edwards, E. J. (2014). Biome Shifts and Niche Evolution in Plants. Annual Review of Ecology, Evolution, and Systematics, 45(1), 547-572.

Doyle, J. A., Manchester, S. R., \& Sauquet, H. (2008). A Seed Related to Myristicaceae in the Early Eocene of Southern England. Systematic Botany, 33(4), 636-646.

Doyle, J. A., Sauquet, H., Scharaschkin, T., \& Le Thomas, A. (2004). Phylogeny, Molecular and Fossil Dating, and Biogeographic History of Annonaceae and Myristicaceae (Magnoliales). International Journal of Plant Sciences, 165(S4), S55-S67.

Edgar, R. C. (2004). MUSCLE: multiple sequence alignment with high accuracy and high throughput. Nucleic Acids Research, 32(5), 1792-1797.

Edwards, E. J., \& Donoghue, M. J. (2013). Is it easy to move and easy to evolve? Evolutionary accessibility and adaptation. Journal of Experimental Botany, 64(13), 4047-4052.

Esquivel-Muelbert, A., Baker, T. R., Dexter, K. G., Lewis, S. L., ter Steege, H., Lopez-Gonzalez, G., Monteagudo Mendoza, A., Brienen, R., Feldpausch, T. R., Pitman, N., Alonso, A., van der Heijden, G., Peña-Claros, M., Ahuite, M., Alexiaides, M., Álvarez Dávila, E., Murakami, A. A., Arroyo, L., Aulestia, M., ... Phillips, O. L. (2017). Seasonal drought limits tree species across the Neotropics. Ecography, 40(5), 618-629.

Faircloth, B. C. (2016). PHYLUCE is a software package for the analysis of conserved genomic loci. Bioinformatics, 32(5), 786-788.

Faircloth, B. C., McCormack, J. E., Crawford, N. G., Harvey, M. G., Brumfield, R. T., \& Glenn, T. C. (2012). Ultraconserved elements anchor thousands of genetic markers spanning multiple evolutionary timescales. Systematic Biology, 61(5), 717-726. 
Fick, S. E., \& Hijmans, R. J. (2017). WorldClim 2: new 1-km spatial resolution climate surfaces for global land areas. International Journal of Climatology, 37(12), 4302-4315.

Forget, P.-M., Milleron, T., Feer, F., Henry, O., \& Dubost, G. (2000). Effects of dispersal pattern and mammalian herbivores on seedling recruitment for Virola michelii (Myristicaceae) in French Guiana. Biotropica, 32(3), 452-462.

Garzione, C. N., Hoke, G. D., Libarkin, J. C., Withers, S., MacFadden, B., Eiler, J., Ghosh, P., \& Mulch, A. (2008). Rise of the Andes. Science, 320(5881), 1304-1307.

Gentry, A. H. (1982). Neotropical floristic diversity: Phytogeographical connections between Central and South America, Pleistocene climatic fluctuations, or an acccident of the Andean orogeny? Annals of the Missouri Botanical Garden, 69(3), 557.

Giraldo, P., Gómez-Posada, C., Martínez, J., \& Kattan, G. (2007). Resource use and seed dispersal by red howler monkeys (Alouatta seniculus) in a Colombian Andean forest. Neotropical Primates, 14(2), 55-64.

Goodwin, Z. A., Harris, D. J., Filer, D., Wood, J. R. I., \& Scotland, R. W. (2015). Widespread mistaken identity in tropical plant collections. Current Biology, 25(22), R1066-R1067.

Guevara Andino, J. E., Pitman, N. C. A., Ter Steege, H., Mogollón, H., Ceron, C., Palacios, W., Oleas, N., \& Fine, P. V. A. (2017). Incorporating phylogenetic information for the definition of floristic districts in hyperdiverse Amazon forests: Implications for conservation. Ecology and Evolution, 7(22), 9639-9650.

Hale, H., Gardner, E. M., Viruel, J., Pokorny, L., \& Johnson, M. G. (2020). Strategies for reducing per-sample costs in target capture sequencing for phylogenomics and population genomics in plants. Applications in Plant Sciences, 8(4), e11337.

Hallé, F., Tomlinson, P. B., \& Zimmermann, M. H. (1978). Architectural variation at the specific level in tropical trees. Tropical Trees as Living Systems, 209-221.

Hijmans, R. J., Van Etten, J., Cheng, J., Mattiuzzi, M., Sumner, M., Greenberg, J. A., Lamigueiro, O. P., Bevan, A., Racine, E. B., Shortridge, A., \& Others. (2015). Package "raster." R Package.

$\mathrm{ftp} / / /$ slartibardfast.gtlib.gatech.edu/pub/CRAN/web/packages/raster/raster.pdf

Hoorn, C., van der Ham, R., de la Parra, F., Salamanca, S., ter Steege, H., Banks, H., Star, W., van Heuven, B. J., Langelaan, R., Carvalho, F. A., Rodriguez-Forero, G., \& Lagomarsino, L. P. (2019). Going north and south: The biogeographic history of two Malvaceae in the wake of Neogene Andean uplift and connectivity between the Americas. Review of Palaeobotany and Palynology, 264, 90-109.

Hoorn, C., Wesselingh, F. P., ter Steege, H., Bermudez, M. A., Mora, A., Sevink, J., Sanmartín, I., Sanchez-Meseguer, A., Anderson, C. L., Figueiredo, J. P., Jaramillo, C., Riff, D., Negri, F. R., Hooghiemstra, H., Lundberg, J., Stadler, T., Särkinen, T., \& Antonelli, A. (2010).

Amazonia through time: Andean uplift, climate change, landscape evolution, and biodiversity. Science, 330(6006), 927-931.

Hughes, C. E. (2016). The tropical Andean plant diversity powerhouse [Review of The tropical 
Andean plant diversity powerhouse]. The New Phytologist, 210(4), 1152-1154.

Hughes, C. E., \& Eastwood, R. (2006). Island radiation on a continental scale: exceptional rates of plant diversification after uplift of the Andes. Proceedings of the National Academy of Sciences of the United States of America, 103(27), 10334-10339.

Hughes, C. E., Eastwood, R. J., \& Donovan Bailey, C. (2006). From famine to feast? Selecting nuclear DNA sequence loci for plant species-level phylogeny reconstruction. Philosophical Transactions of the Royal Society B, 361(1465), 211-225.

Hutter, C. R., Cobb, K. A., Portik, D. M., Travers, S. L., Wood, P. L., \& Brown, R. M. (2019). FrogCap: A modular sequence capture probe set for phylogenomics and population genetics for all frogs, assessed across multiple phylogenetic scales. In Cold Spring Harbor Laboratory (p. 825307). https://doi.org/10.1101/825307

Jantzen, J. R., Amarasinghe, P., Folk, R. A., Reginato, M., Michelangeli, F. A., Soltis, D. E., Cellinese, N., \& Soltis, P. S. (2020). A two-tier bioinformatic pipeline to develop probes for target capture of nuclear loci with applications in Melastomataceae. Applications in Plant Sciences, e11345.

Jaramillo, T. S., Muriel, P., \& Balslev, H. (2004). Myristicaceae. In G. W. Harling \& L. Andersson (Eds.), Flora of Ecuador (Vol. 72, pp. 1-101).

Jaramillo-Vivanco, T. S., \& Balslev, H. (2020). Revision of Otoba (Myristicaceae). Phytotaxa, 441(2), 143-175.

Jardim, M. A. G., \& Mota, C. G. da. (2007). Biologia floral de Virola surinamensis (Rol.) Warb. (Myristicaceae). Revista Árvore, 31(6), 1155-1162.

Johnson, M. G., Gardner, E. M., Liu, Y., Medina, R., Goffinet, B., Shaw, A. J., Zerega, N. J. C., \& Wickett, N. J. (2016). HybPiper: Extracting coding sequence and introns for phylogenetics from high-throughput sequencing reads using target enrichment. Applications in Plant Sciences, 4(7), apps.1600016.

Johnson, M. G., Pokorny, L., Dodsworth, S., Botigué, L. R., Cowan, R. S., Devault, A., Eiserhardt, W. L., Epitawalage, N., Forest, F., Kim, J. T., Leebens-Mack, J. H., Leitch, I. J., Maurin, O., Soltis, D. E., Soltis, P. S., Wong, G. K.-S., Baker, W. J., \& Wickett, N. J. (2019). A universal probe set for targeted sequencing of 353 nuclear genes from any flowering plant designed using k-Medoids clustering. Systematic Biology, 68(4), 594-606.

Katoh, K., \& Standley, D. M. (2013). MAFFT multiple sequence alignment software version 7: improvements in performance and usability. Molecular Biology and Evolution, 30(4), 772780.

Khabbazian, M., Kriebel, R., Rohe, K., \& Ané, C. (2016). Fast and accurate detection of evolutionary shifts in Ornstein-Uhlenbeck models. Methods in Ecology and Evolution / British Ecological Society, 7(7), 811-824.

Koehler, K., Center, A., \& Cavender-Bares, J. (2012). Evidence for a freezing tolerance-growth rate trade-off in the live oaks (Quercus series Virentes) across the tropical-temperate divide. The New Phytologist, 193(3), 730-744. 
Lagomarsino, L. P., Condamine, F. L., Antonelli, A., Mulch, A., \& Davis, C. C. (2016). The abiotic and biotic drivers of rapid diversification in Andean bellflowers (Campanulaceae). The New Phytologist. https://doi.org/10.1111/nph.13920

Lanfear, R., Frandsen, P. B., Wright, A. M., Senfeld, T., \& Calcott, B. (2017). PartitionFinder 2: New Methods for Selecting Partitioned Models of Evolution for Molecular and Morphological Phylogenetic Analyses. Molecular Biology and Evolution, 34(3), 772-773.

Larsson, A. (2014). AliView: a fast and lightweight alignment viewer and editor for large datasets. Bioinformatics , 30(22), 3276-3278.

Lavin, M., \& Luckow, M. (1993). Origins and relationships of tropical north America in the context of the boreotropics hypothesis. American Journal of Botany, 80(1), 1-14.

Linan, A. G., Myers, J. A., Edwards, C. E., Zanne, A. E., Smith, S. A., Arellano, G., Cayola, L., Farfan-Ríos, W., Fuentes, A. F., Garcia-Cabrera, K., Gonzales-Caro, S., Isabel Loza, M., Macía, M. J., Malhi, Y., Nieto-Ariza, B., Revilla, N. S., Silman, M., \& Sebastián Tello, J. (2021). The evolutionary assembly of forest communities along environmental gradients: recent diversification or sorting of pre-adapted clades? In Cold Spring Harbor Laboratory (p. 2020.12.22.424032). https://doi.org/10.1101/2020.12.22.424032

Macía, M. J. (2008). Woody plants diversity, floristic composition and land use history in the Amazonian rain forests of Madidi National Park, Bolivia. Biodiversity and Conservation, 17(11), 2671-2690.

Madriñán, S., Cortés, A. J., \& Richardson, J. E. (2013). Páramo is the world's fastest evolving and coolest biodiversity hotspot. Frontiers in Genetics, 4, 192.

Magallón, S., Gómez-Acevedo, S., Sánchez-Reyes, L. L., \& Hernández-Hernández, T. (2015). A metacalibrated time-tree documents the early rise of flowering plant phylogenetic diversity. The New Phytologist, 207(2), 437-453.

Martínez, C., Jaramillo, C., Correa-Metrío, A., Crepet, W., Moreno, J. E., Aliaga, A., Moreno, F., Ibañez-Mejia, M., \& Bush, M. B. (2020). Neogene precipitation, vegetation, and elevation history of the Central Andean Plateau. Science Advances, 6(35), eaaz4724.

Massana, K. A., Beaulieu, J. M., Matzke, N. J., \& O'Meara, B. C. (2015). Non-null effects of the null range in biogeographic models: Exploring parameter estimation in the DEC model. In bioRxiv (p. 026914). https://doi.org/10.1101/026914

Massoni, J., Couvreur, T. L. P., \& Sauquet, H. (2015). Five major shifts of diversification through the long evolutionary history of Magnoliidae (angiosperms). BMC Evolutionary Biology, 15, 49.

Massoni, J., Forest, F., \& Sauquet, H. (2014). Increased sampling of both genes and taxa improves resolution of phylogenetic relationships within Magnoliidae, a large and earlydiverging clade of angiosperms. Molecular Phylogenetics and Evolution, 70, 84-93.

Matzke, N. J. (2014). Model selection in historical biogeography reveals that founder-event speciation is a crucial process in island clades. Systematic Biology, 63(6), 951-970.

Melo, F. P. L., Rodriguez-Herrera, B., Chazdon, R. L., Medellin, R. A., \& Ceballos, G. G. (2009). 
Small tent-roosting bats promote dispersal of large-seeded plants in a Neotropical forest. Biotropica, 41(6), 737-743.

Montes, C., Cardona, A., McFadden, R., Morón, S. E., Silva, C. A., Restrepo-Moreno, S., Ramírez, D. A., Hoyos, N., Wilson, J., Farris, D., Bayona, G. A., Jaramillo, C. A., Valencia, V., Bryan, J., \& Flores, J. A. (2012). Evidence for middle Eocene and younger land emergence in central Panama: Implications for Isthmus closure. GSA Bulletin, 124(5-6), 780-799.

Moreira, J. I., Riba-Hernández, P., \& Lobo, J. A. (2017). Toucans (Ramphastos ambiguus) facilitate resilience against seed dispersal limitation to a large-seeded tree (Virola surinamensis) in a human-modified landscape. Biotropica, 49(4), 502-510.

Morley, R. J., \& Dick, C. W. (2003). Missing fossils, molecular clocks, and the origin of the Melastomataceae. American Journal of Botany, 90(11), 1638-1644.

Muller-Landau, H. C., Wright, S. J., Calderón, O., Condit, R., \& Hubbell, S. P. (2008). Interspecific variation in primary seed dispersal in a tropical forest. The Journal of Ecology, 96(4), 653-667.

Myster, R. W. (2020). Disturbance and response in the Andean cloud forest: a conceptual review. The Botanical Review, 86, 119-135.

Nathan, R. (2006). Long-distance dispersal of plants. Science, 313(5788), 786-788.

Nathan, R., Schurr, F. M., Spiegel, O., Steinitz, O., Trakhtenbrot, A., \& Tsoar, A. (2008). Mechanisms of long-distance seed dispersal. Trends in Ecology \& Evolution, 23(11), 638647.

Nuñez-Iturri, G., \& Howe, H. F. (2007). Bushmeat and the fate of trees with seeds dispersed by large primates in a lowland rain forest in Western Amazonia. Biotropica, 39(3), 348-354.

O'Dea, A., Lessios, H. A., Coates, A. G., Eytan, R. I., Restrepo-Moreno, S. A., Cione, A. L., Collins, L. S., de Queiroz, A., Farris, D. W., Norris, R. D., Stallard, R. F., Woodburne, M. O., Aguilera, O., Aubry, M.-P., Berggren, W. A., Budd, A. F., Cozzuol, M. A., Coppard, S. E., Duque-Caro, H., ... Jackson, J. B. C. (2016). Formation of the Isthmus of Panama. Science Advances, 2(8), e1600883.

Ogburn, M., \& Edwards, E. J. (2015). Life history lability underlies rapid climate niche evolution in the angiosperm clade Montiaceae. Molecular Phylogenetics and Evolution, 92, 181-192.

One Thousand Plant Transcriptomes Initiative. (2019). One thousand plant transcriptomes and the phylogenomics of green plants. Nature, 574(7780), 679-685.

Pennington, R. T., Lavin, M., Särkinen, T., Lewis, G. P., Klitgaard, B. B., \& Hughes, C. E. (2010). Contrasting plant diversification histories within the Andean biodiversity hotspot. Proceedings of the National Academy of Sciences of the United States of America, 107(31), 13783-13787.

Pérez-Escobar, O. A., Gottschling, M., Chomicki, G., Condamine, F. L., Klitgård, B. B., Pansarin, E., \& Gerlach, G. (2017). Andean mountain building did not preclude dispersal of lowland epiphytic orchids in the Neotropics. Scientific Reports, 7(1), 4919. 
Pirie, M. D., Maas, P. J. M., Wilschut, R. A., Melchers-Sharrott, H., \& Chatrou, L. W. (2018).

Parallel diversifications of Cremastosperma and Mosannona (Annonaceae), tropical rainforest trees tracking Neogene upheaval of South America. Royal Society Open Science, 5(1), 171561.

Pitman, N. C. A., Vargas, P. N., \& Terborgh, J. W. (2017). Árboles comunes de los bosques inundados de Madre de Dios. Biodiversidad Amazónica Vol 5, 1(1).

http://revistas.unamad.edu.pe/index.php/Biodiversidad/article/view/45

Pouchon, C., Fernández, A., Nassar, J. M., Boyer, F., Aubert, S., Lavergne, S., \& Mavárez, J. (2018). Phylogenomic Analysis of the Explosive Adaptive Radiation of the Espeletia Complex (Asteraceae) in the Tropical Andes. Systematic Biology, 67(6), 1041-1060.

Qiu, Y.-L., Li, L., Hendry, T. A., Li, R., Taylor, D. W., Issa, M. J., Ronen, A. J., Vekaria, M. L., \& White, A. M. (2006). Reconstructing the basal angiosperm phylogeny: evaluating information content of mitochondrial genes. Taxon, 55(4), 837-856.

Queenborough, S. A., Burslem, D. F. R. P., Garwood, N. C., \& Valencia, R. (2007a). Neighborhood and community interactions determine the spatial pattern of tropical tree seedling survival. Ecology, 88(9), 2248-2258.

Queenborough, S. A., Burslem, D. F. R. P., Garwood, N. C., \& Valencia, R. (2007b). Habitat niche partitioning by 16 species of Myristicaceae in Amazonian Ecuador. Plant Ecology, 192(2), 193-207.

Rambaut, A., Drummond, A. J., Xie, D., Baele, G., \& Suchard, M. A. (2018). Posterior Summarization in Bayesian Phylogenetics Using Tracer 1.7. Systematic Biology, 67(5), 901-904.

Revell, L. J. (2012). phytools: an R package for phylogenetic comparative biology (and other things). Methods in Ecology and Evolution / British Ecological Society, 3(2), 217-223.

Russo, S. E. (2003). Responses of dispersal agents to tree and fruit traits in Virola calophylla (Myristicaceae): implications for selection. Oecologia, 136(1), 80-87.

Santamaría-Aguilar, D., Jiménez, J. E., \& Aguilar, R. (2019). Otoba vespertilio (Myristicaceae), una especie nueva de Mesoamérica. Brittonia, 71(4), 369-380.

Särkinen, T., Pennington, R. T., Lavin, M., Simon, M. F., \& Hughes, C. E. (2012). Evolutionary islands in the Andes: persistence and isolation explain high endemism in Andean dry tropical forests. Journal of Biogeography, 39(5), 884-900.

Särkinen, T., Staats, M., Richardson, J. E., Cowan, R. S., \& Bakker, F. T. (2012). How to open the treasure chest? Optimising DNA extraction from herbarium specimens. PloS One, 7(8), e43808.

Sauquet, H., Doyle, J. A., Scharaschkin, T., Borsch, T., Hilu, K. W., Chatrou, L. W., \& Le Thomas, A. (2003). Phylogenetic analysis of Magnoliales and Myristicaceae based on multiple data sets: implications for character evolution. Botanical Journal of the Linnean Society. Linnean Society of London, 142(2), 125-186.

Sauquet, H., \& Le Thomas, A. (2003). Pollen diversity and evolution in Myristicaceae 
(Magnoliales). International Journal of Plant Sciences, 164(4), 613-628.

Sharma, M. V., \& Armstrong, J. E. (2013). Pollination of Myristica and other nutmegs in natural populations. Tropical Conservation Science, 6(5), 595-607.

Simon, M. F., Grether, R., de Queiroz, L. P., Skema, C., Pennington, R. T., \& Hughes, C. E. (2009). Recent assembly of the Cerrado, a neotropical plant diversity hotspot, by in situ evolution of adaptations to fire. Proceedings of the National Academy of Sciences of the United States of America, 106(48), 20359-20364.

Smith, S. A., \& O'Meara, B. C. (2012). treePL: divergence time estimation using penalized likelihood for large phylogenies. Bioinformatics , 28(20), 2689-2690.

Soltis, D. E., Gitzendanner, M. A., \& Soltis, P. S. (2007). A 567 $\square$ taxon data set for angiosperms: The challenges posed by Bayesian analyses of large data sets. International Journal of Plant Sciences, 168(2), 137-157.

Štorchová, H., Hrdličková, R., Chrtek, J., Jr., Tetera, M., Fitze, D., \& Fehrer, J. (2000). An improved method of DNA isolation from plants collected in the field and conserved in saturated $\mathrm{NaCl} / \mathrm{CTAB}$ solution. Taxon, 49(1), 79-84.

Swamy, V. (2017). Forest composition and spatial patterns across a Western Amazonian River basin: The influence of plant-animal interactions. In R. W. Myster (Ed.), Forest structure, function and dynamics in Western Amazonia (Vol. 31, pp. 159-180). John Wiley \& Sons, Ltd.

Terborgh, J., Alvarez-Loayza, P., Dexter, K., Cornejo, F., \& Carrasco, C. (2011). Decomposing dispersal limitation: limits on fecundity or seed distribution? The Journal of Ecology, 99(4), 935-944.

ter Steege, H., Pitman, N. C. A., Phillips, O. L., Chave, J., Sabatier, D., Duque, A., Molino, J.-F., Prévost, M.-F., Spichiger, R., Castellanos, H., von Hildebrand, P., \& Vásquez, R. (2006). Continental-scale patterns of canopy tree composition and function across Amazonia. Nature, 443(7110), 444-447.

Thomas, D. C., Tang, C. C., \& Saunders, R. M. K. (2017). Historical biogeography ofGoniothalamusand Annonaceae tribe Annoneae: dispersal-vicariance patterns in tropical Asia and intercontinental tropical disjunctions revisited. Journal of Biogeography, 44(12), 2862-2876.

Valcárcel, V., \& Wen, J. (2019). Chloroplast phylogenomic data support Eocene amphi $\square$ Pacific early radiation for the Asian Palmate core Araliaceae. Journal of Systematics and Evolution, 57(6), 547-560.

Warren, D. L., Matzke, N., Cardillo, M., Baumgartner, J., Beaumont, L., Huron, N., Simões, M., \& Dinnage, R. (2019). ENMTools (Software Package). URL: Https://github. com/dan/warren/ENMTools. Doi, 10. https://rdrr.io/github/danlwarren/ENMTools/f/Readme.Rmd Wittmann, F., Schongart, J., Montero, J. C., Motzer, T., Junk, W. J., Piedade, M. T. F., Queiroz, H. L., \& Worbes, M. (2006). Tree species composition and diversity gradients in white-water 
forests across the Amazon Basin. Journal of Biogeography, 33(8), 1334-1347.

Wolfe, J. A. (1975). Some Aspects of Plant Geography of the Northern Hemisphere During the Late Cretaceous and Tertiary. Annals of the Missouri Botanical Garden. Missouri Botanical Garden, 62(2), 264-279.

Wolfe, J. A. (1977). Paleogene floras from the Gulf of Alaska region (No. 997). U.S. Govt. Print. Off.,. https://doi.org/10.3133/pp997

Woodroffe, C. D., \& Grindrod, J. (1991). Mangrove Biogeography: The Role of Quaternary Environmental and Sea-Level Change. Journal of Biogeography, 18(5), 479-492.

Xue, B., Tan, Y.-H., Thomas, D. C., Chaowasku, T., Hou, X.-L., \& Saunders, R. M. K. (2018). A new Annonaceae genus, Wuodendron, provides support for a post-boreotropical origin of the Asian-Neotropical disjunction in the tribe Miliuseae. Taxon, 67(2), 250-266.

\section{Biosketch}

The Lagomarsino Lab studies Neotropical plant evolution (more at http://www.lauralago.net/). L.F., D.A.S.A, and L.P.L. conceived the ideas; all authors collected data; L.F., D.S., and L.P.L analysed data; and L.F. and L.P.L led the writing. 


\section{Flgure Legends}

Fig. 1. Morphological diversity of Otoba. A-C) Floral diversity. A) Staminate and B) pistillate flowers of $O$. gordoniifolia; C) Infloresence of Central American O. novogranatensis. D-F) Fruit diversity. D) Fruit from South American O. novogranatensis showing whitish aril and E) from Central American $O$. novogranatensis showing red aril. F) Unopened capsules of $O$. gordoniifolia. G-I) Vegetative diversity. G) Branch and H) stem cut of Central American $O$. novogranatensis, the latter showing characteristic red exudate. I) Leaf of $O$. parvifolia, showing vernation lines. (Photo credits: $A, B$, and F by Rudy Gelis, downloaded from iNaturalist with permission; C, E, G, and H by Reinaldo Aguilar; D by Timothy Paine; and I by John Janovec.)

Fig. 2. Results of ML analyses of concatenated chloroplast and nuclear data. The tree on the right shows branch lengths; the cladogram on the left shows the branching pattern for the ingroup + Mryistica and support values at nodes with <100 bootstrap support (all outgroup relationships were fully supported).

Fig. 3. Time-calibrated plastid phylogeny of Myristicaceae depicting global biogeography. The phylogeny represents the maximum clade credibility tree of a BEAST2 analysis using calibration points from Magallón et al (2015). Values at nodes represent posterior probabilities, with dashes representing <50 PP; support for relationships below genus level are not included except in instances of deep splits with a genus, but are available in Appendix S6, as are the 95\% HPD for the date at each node. Ancestral area reconstructions as inferred by the best-fit DIVA-like model in BioGeoBEARS are depicted in pie charts at each node, with colors corresponding to the areas in the map at top left (dark blue= Africa; orange = Asia; red= Neotropics; yellow = both Neotropics and Asia; light blue = both Africa and Asia). The previously understood major clades of Myristicaceae from Sauquet et al. (2003) are indicated by the colored bars at the right of the phylogeny (yellow = pycnanthoids; purple = mauloutchioids; green = myristicoids) .

Fig. 4. Ancestral area reconstructions in Otoba for (A) Central America versus South America and $(B)$ western Andes and Central America versus eastern Andes and the Amazon. Pie charts at nodes display the probability that the ancestor occupied a given range. Maps to the left of each tree are color coded to correspond with the geographic areas coded on the tree. In $(A)$, orange $=$ South America, purple $=$ Central America, and red $=$ both Central and South America; the distribution of each species in Central and/or South America is additionally reflected in the color-coded boxes at the tips of the tree. In (B), pink = western Andes and Central America, and mustard = eastern Andes and the Amazon; the Andes are represented in black.

Fig. 5. Niche evolution in Otoba is dynamic. A) Ancestral state reconstruction of average elevation $(\mathrm{m})$ in Otoba demonstrates the wide range of elevational preferences among species, 
ranging from $404 \mathrm{~m}$ in 0 . acuminata to $1380 \mathrm{~m}$ in 0 . gordoniifolia. At right, species distributions modeled in Maxent demonstrate the variation in potential niche suitability in the Neotropics. B) Orstein-Uhlenbeck models implement in I1ou infer four shifts in climate space, denoted by asterisk at node with bootstrap value, corresponding to the western Amazonia clade; $O$. latialata; O. gordoniifolia; and a Central American clade comprising O. acuminata and $O$. novogranatensis (CA). C) Phylomorphospace of phylogenetic PCA of BIOCLIM variables. 